\title{
Patient Willingness to Consent to Mobile Phone Data Collection for Mental Health Apps: Structured Questionnaire
}

Daniel Di Matteo ${ }^{1}$, MASc; Alexa Fine ${ }^{2}$, BSc (Hons); Kathryn Fotinos ${ }^{2}$, BSc (Hons); Jonathan Rose ${ }^{1}$, PhD, FRSC; Martin Katzman ${ }^{2,3,4,5}$, MD, FRCPC

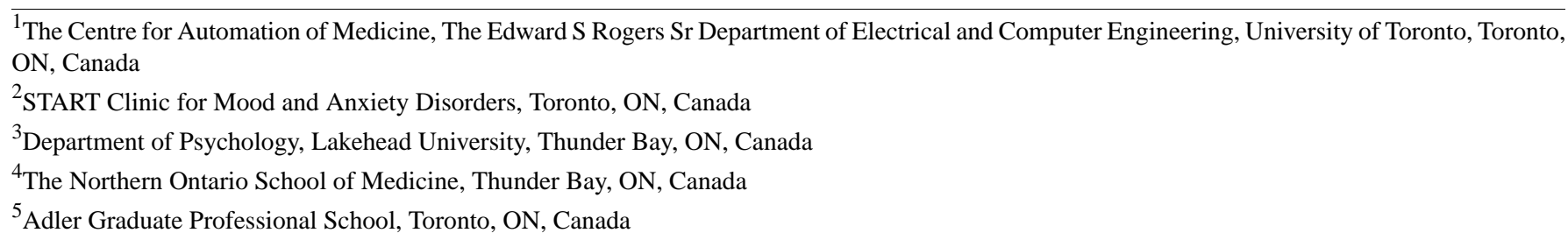

Corresponding Author:

Daniel Di Matteo, MASc

The Centre for Automation of Medicine

The Edward S Rogers Sr Department of Electrical and Computer Engineering

University of Toronto

DL Pratt Building

6 King's College Road

Toronto, ON,

Canada

Phone: 14169786992

Fax: 14169468734

Email: dandm@ece.utoronto.ca

\section{Abstract}

Background: It has become possible to use data from a patient's mobile phone as an adjunct or alternative to the traditional self-report and interview methods of symptom assessment in psychiatry. Mobile data-based assessment is possible because of the large amounts of diverse information available from a modern mobile phone, including geolocation, screen activity, physical motion, and communication activity. This data may offer much more fine-grained insight into mental state than traditional methods, and so we are motivated to pursue research in this direction. However, passive data retrieval could be an unwelcome invasion of privacy, and some may not consent to such observation. It is therefore important to measure patients' willingness to consent to such observation if this approach is to be considered for general use.

Objective: The aim of this study was to measure the ownership rates of mobile phones within the patient population, measure the patient population's willingness to have their mobile phone used as an experimental assessment tool for their mental health disorder, and, finally, to determine how likely patients would be to provide consent for each individual source of mobile phone-collectible data across the variety of potential data sources.

Methods: New patients referred to a tertiary care mood and anxiety disorder clinic from August 2016 to October 2017 completed a survey designed to measure their mobile phone ownership, use, and willingness to install a mental health monitoring app and provide relevant data through the app.

Results: Of the 82 respondents, $70(85 \%)$ reported owning an internet-connected mobile phone. When asked about installing a hypothetical mobile phone app to assess their mental health disorder, $41 \%$ (33/80) responded with complete willingness to install with another $43 \%$ (34/80) indicating potential willingness to install such an app. Willingness to give permissions for specific types of data varied by data source, with respondents least willing to consent to audio recording and analysis (19\% [15/80] willing respondents, $31 \%$ [25/80] potentially willing) and most willing to consent to observation of the mobile phone screen being on or off (46\% [36/79] willing respondents and $23 \%$ [18/79] potentially willing).

Conclusions: The patients surveyed had a high incidence of ownership of internet-connected mobile phones, which suggests some plausibility for the general approach of mental health state inference through mobile phone data. Patients were also relatively 
willing to consent to data collection from sources that were less personal but expressed less willingness for the most personal communication and location data.

(JMIR Ment Health 2018;5(3):e56) doi: 10.2196/mental.9539

\section{KEYWORDS}

passive sensing; mobile phone sensing; psychiatric assessment; mood and anxiety disorders; digital privacy; mobile apps; mobile phone; consent

\section{Introduction}

The assessment of mood and anxiety disorders is most commonly performed through clinician interview of the patient or patient self-report. These assessments question patients about their feelings and actions in situations throughout their daily life, asking patients to report the intensity and severity of their symptoms. A review by Meyer et al [1] found that although psychological and medical tests/assessments are valid overall, they have varying degrees of validity, from very low to very high, due to variations in assessment style and responses. Patients may be unwilling or unable to answer accurately due to inaccuracy of recollection [2], psychopathology and/or biases $[3,4]$, ambiguity in the questions, or lack of comfort with their clinician, among other factors. Furthermore, the rating scales employed as part of these assessments are typically not objective - for example, asking the patient to rate their feelings of fear or anxiety, for which no objective measures exist.

An alternative to assessing mental disorders based on descriptions of feelings would be an assessment in which patient behaviors are observed and qualified as indicating increased or decreased severity of the symptoms of the patient's mental disorder. Researchers have begun taking steps toward behavior-based assessments of mental disorders by employing mobile phones as sensing platforms to directly measure or otherwise infer behaviors. Mobile phones are an excellent tool for this purpose, since most owners carry them throughout their day [5] and a combination of sensor data and software techniques can be used to infer high-level behavior and contextual awareness [5-9]. Perhaps most importantly, a mobile phone offers the potential to collect objective data from the patient in contrast to the subjective information provided in interviews or self-reports. The data can be considered objective because there is no human interpretation or mediation of information that comes from sensors that directly measure physical properties. This objectivity of the measurement gives rise to the potential for objective assessment of mental health based on those data [10].

Prior research with this style of passively-sensed, mobile phone-based assessment has shown the ability to measure patients' mental health states relating to disorders such as depression [11] and bipolar disorder [12,13]. Abdullah et al [12] used mobile phone data to assess the social rhythm metric, a marker of stability for individuals with bipolar disorder. They passively recorded geolocation, ambient light levels, communication activity, and ambient audio to infer the metric. Faurhollt-Jepsen et al [11] reported that they could classify the affective state of patients with bipolar disorder by analyzing features of the patients' voices as recorded by the mobile phone app developed. Ben-Zeev et al [13] demonstrated that changes in depression severity were associated with changes in physical activity, speech duration, and sleep duration, all of which were measured passively through a mobile phone app. Place et al [15] generated behavioral indicators from mobile phone-collected data that were predictive of clinically assessed symptoms of depression and posttraumatic stress disorder [15].

While these techniques show promise as novel, objective assessment tools, they rely upon the collection and processing of large amounts of private data from a patient's mobile phone. This presents several challenges when requesting patient consent to provide this data. Records of a patient's whereabouts and communications could result in health care providers being subpoenaed for these records by law enforcement agencies. As a result, patients may not be willing to consent to wholesale collection of these data for fear of potential legal ramifications. Patients may also feel uneasy knowing that their health care providers have the ability to scrutinize their actions and communications on a very fine-grained level. This is a specific concern for patients with anxiety disorder. In particular, for those with social anxiety disorder, where a source of anxiety is the fear of judgment from others [16], personal data collected from a mobile phone could potentially form the basis of that judgment. Furthermore, a patient may also fear the possibility that their data could accidentally become public and reveal confidential thoughts, feelings, and behaviors or that perhaps there could be legal implications if the government were to have access to the data [17].

For the researchers and practitioners interested in designing, experimenting with, and deploying these kinds of mobile phone-based assessment tools, it will be important to have a sense of the patient population's willingness to consent to the necessary data collection. A number of studies have surveyed the general consumer population to determine the adoption of Internet of Things [18-20] and wearable technologies [21,22] for health care purposes, and all clearly identified privacy concerns surrounding the data collected by these technologies. However, it is important to know specifically which sources of data available for collection on mobile phones are of most concern and therefore least likely to achieve consent. This question was also raised by Torous et al [23], who, in their study of patient interest in using mobile apps to monitor their mental health conditions, state that they did not address specifically to which sources of information patients would be willing to grant access. This information would allow researchers and developers to build systems that do not rely on unlikely-to-consent sources of data or to do extra work to find ways to address the concerns of patients on particular sources of data collection. It also gives insight into potential barriers that clinicians and researchers 
would need to address in order to deploy such systems in a health care setting.

The objectives of this research were as follows: first, since mobile phone-based assessment requires that patients own a mobile phone and use it regularly, it is necessary to measure the ownership rates of mobile phones within the patient population. We also seek to gauge the patient population's willingness to enroll in research studies in which their mobile phone would be used as an experimental assessment tool for their mental health disorder. Finally, and most importantly, we seek to determine how likely patients would be to provide consent for each individual source of mobile phone-collectible data across the wide variety of potential data sources.

\section{Methods}

\section{Participants and Procedure}

Participants included 82 individuals referred to the START (Stress, Trauma, Anxiety, Rehabilitation, Treatment) Clinic for Mood and Anxiety Disorders, a tertiary care mood and anxiety disorder clinic for the management of their symptoms, located in the city of Toronto, Ontario, Canada. Male and female genders were equally represented with $46 \%$ (38/82) males, $46 \%$ (38/82) females, and 7\% (6/82) individuals who did not respond to a question on gender. The average age of the participants was 41 (SD 14.0) years old. All new intakes and existing patients (ie, any patients in the waiting room) from August 2016 to October 2017 were recruited for the survey while waiting for their appointment with a clinician. Patients were asked to complete a pen-and-paper questionnaire designed to achieve the goals stated above. The questionnaire underwent ethics review by Optimum Clinical Research (protocol number WS2382578), and all respondents provided informed consent before completing the questionnaire.

\section{Materials}

The questionnaire designed for this study consisted of 13 self-report questions. The introduction to the questionnaire provides context to the questions which follow by presenting the concept of mobile phone apps as a potential supplement or replacement to questionnaire-based methods of mental health assessment. It is explained that the collection and analysis of data from patients' mobile phones may assist their clinicians in providing better care yet may also impact their privacy. The questions, therefore, are to survey people's willingness to provide sources of information to clinicians and researchers in a scenario where a hypothetical mobile phone app were installed onto their personal mobile phone.

The questions are listed in Textbox 1. Questions 1 through 3 assess general mobile phone use, ownership information, and willingness to install an app that might help with mental health. Questions 4 through 12 ask respondents if they would be willing to share a specific source of data available on their mobile phone. The final question asks which specific brand of phone the respondent uses. For the 2 most potentially rich sources of information, SMS (short message service, or text) messages and raw ambient audio recordings made using the device's microphone, multiple questions are posed in which the amount of information and granularity of the data collection are varied. For example, question 5 asks if respondents would allow collection of SMS metadata (which doesn't contain the content of the message but surrounding information such as who the message was sent to/from and when message occurred), while question 6 asks respondents if they would allow analysis into the contents of their messages for the purposes of extracting potentially clinically relevant words.

Questions 10 through 12 are audio-related. Question 10, concerning the least detailed of the 3 audio data sources, asks respondents if they would share audio metadata, while question 11 concerns willingness to have speech recognition (word detection) performed upon their audio. Question 12 assesses willingness on the most detailed personal data: the unrestrained analysis of ambient audio.

\section{Analysis}

Responses to questions 1 through 12 were coded as ordinal variables with 2 (yes and no responses) or 3 levels (yes, maybe, and no responses). When respondents chose to use the other categories of response and provided free-form text, these responses were interpreted as either a yes, maybe, or no response and coded accordingly. Responses to question 13 (on the phone brand type) were coded as a categorical variable. To test for correlation between responses to questions and respondent age, the Spearman rank correlation coefficient (Spearman $\rho$ ) was computed along with $P$ values to test against the alternative hypothesis that the correlation was nonzero (using the exact permutation test). To test for associations between responses to questions and respondent gender, responses were cross-tabulated by gender and a chi-square test for independence was performed (2-tailed). All statistics and tests were computed using MATLAB software version 2014b (MathWorks). 
Textbox 1. Survey questions.

1. Do you own a mobile phone and use it daily?

(a) Yes, (b) Yes, but not daily, (c) No

2. Do you connect to the internet on your mobile phone, either using a mobile data plan or Wi-Fi?

(a) Yes, (b) No

3. Would you be willing to install and use a mobile phone app to help your doctor better diagnose mental health problems and/or provide treatment?

(a) Yes, (b) Maybe, but I would need to know more information first, (c) No, (d) Other-specify

4. Would you be willing to have the app collect and share your location? This would use your mobile phone's Global Positioning System and would pinpoint your location on a map from time to time throughout the day.

(a) Yes (b) Maybe, but I would need to know more information first (c) No (d) Other-specify

5. Would you be willing to have the app record the number of contacts you call or send SMS (text messages) to and the dates and times when you phone or text them? The identities of your contacts would not be shared.

(a) Yes, (b) Maybe, but I would need to know more information first, (c) No, (d) Other-specify

6. Would you be willing to have the app read the contents of your text messages to look for keywords related to mental health? (For example, looking for the use of words like "tired," "depressed," or "happy.") The whole text messages would not be shared, only detected keywords.

(a) Yes, (b) Maybe, but I would need to know more information first, (c) No, (d) Other-specify

7. Would you be willing to have the app record every time you create a calendar entry in your calendar app? The specifics of the calendar entry or event would not be shared, only the date and time that you create or modify it.

(a) Yes, (b) Maybe, but I would need to know more information first, (c) No, (d) Other-specify

8. Would you be willing to have the app record every time you turn your phone's screen on or off (using the power or lock button)?

(a) Yes, (b) Maybe, but I would need to know more information first, (c) No, (d) Other-specify

9. Would you be willing to have the app use its sensors to try and detect if and when you are walking, running, in a car, or standing still?

(a) Yes, (b) Maybe, but I would need to know more information first, (c) No, (d) Other-specify

10. Would you be willing to have the app occasionally turn on and use the phone's microphone to record the sounds of your surroundings? This audio would be used by the app to try and classify your surrounding as loud, quiet, or busy, but it would not attempt to recognize any words that you or people around you speak nor would it be listened to by humans. It would not record your phone calls, only ambient audio from time to time when you are not making a phone call.

(a) Yes, (b) Maybe, but I would need to know more information first, (c) No, (d) Other-specify

11. Consider the same scenario as question 10 , but in this case the app will also detect and recognize specific words being spoken aloud by you or anyone else present in the recording. The app would attempt to recognize specific keywords like "tired," "depressed," or "happy." This speech recognition would be done in software by the app, and the audio will never be listened to by humans.

(a) Yes, (b) Maybe, but I would need to know more information first, (c) No, (d) Other-specify

12. Consider the same scenario as question 11, but in this case the app is also able to perform any software-based processing to the recorded audio in order detect things that may be relevant to your mental health. This processing (in whatever form) would be done in software by the app, and the audio recordings will never be listened to by humans, nor will humans ever read a transcript of the recordings.

(a) Yes, (b) Maybe, but I would need to know more information first, (c) No, (d) Other-specify

13. What type of phone do you use daily? If you use multiple phones (work and personal), please select whichever corresponds to your personal phone.

(a) iPhone, (b) Android, (c) Blackberry, (d) Windows Mobile phone, (e) Other-specify

\section{Results}

Of the 82 respondents, $73(89 \%)$ reporting owning a mobile phone and using it daily (question 1). Rates of internet usage are also high, with $85 \%(70 / 82)$ of respondents reporting that they connect to the internet using their mobile phone (question 2). All respondents reported owning either iPhone, Android, Blackberry, or Windows Mobile mobile phones; Apple iPhones constituted 45\% (35/78) of all mobile phones, Android devices constituted 57\% (37/78), Blackberry constituted 6\% (5/78), and Windows Mobile the remaining 1\% (1/78) (question 13). Regarding question 3 , willingness to install and use a mobile phone app to help their doctor better diagnose mental health problems and/or provide treatment, $41 \%$ of respondents (33/80) indicated that they would be willing to install and use such an app, with another $43 \%$ of respondents (34/80) indicating that they may be willing to use such an app, provided they were given more information about how the app functioned. Only $16 \%$ respondents (13/80) indicated absolute unwillingness to use such an app. Table 1 presents how responses to these questions (questions 1, 2, 3, and 13) correlate with respondent age and how the responses are associated with respondent gender. 
Survey questions 4 through 12 asked respondents if they would be willing to grant the hypothetical mental health monitoring app permission to collect a variety of data sources from their mobile phone. The responses corresponding to each permission (data source) are presented in Table 2. Figure 1 provides a graphical representation of this data, along with respondent willingness to install the app. It is worth noting that nearly none of the survey questions were strongly correlated with respondent age or associated with respondent gender. There is a weak positive correlation, however, between willingness to consent to audio recording and respondent age.

Table 1. Correlation with respondent age and association with respondent gender for mobile phone statistics and general willingness to install a mental health monitoring app.

\begin{tabular}{lllll}
\hline Question topic & \multicolumn{2}{c}{ Correlation with respondent age } & \multicolumn{2}{c}{ Association with respondent gender } \\
& $\rho$ & $P$ value & $\mathrm{X}^{2}{ }^{P}$ & \multicolumn{2}{c}{ value } \\
\hline Mobile phone ownership (Q1) & 0.08 & .50 & 2.81 & .24 \\
Internet-connected mobile phone usage (Q2) & -0.09 & .46 & 1.58 & .21 \\
Mobile phone types owned (Q13) & -0.10 & .43 & 1.52 & .68 \\
Respondent willingness to install a mental health monitoring app (Q3) & 0.10 & .44 & 1.86 & .39 \\
\hline
\end{tabular}

Table 2. Survey respondent willingness to grant permission by category.

\begin{tabular}{llllllll}
\hline Permission & \multicolumn{2}{c}{ Willing to grant permission, $\mathrm{n}(\%)$} & \multicolumn{2}{c}{ Correlation with respondent age } & \multicolumn{2}{c}{ Association with respondent gender } \\
& Yes & Maybe & No & $\rho$ & $P$ value & $\mathrm{X}^{2}{ }^{2}$ & $P$ value \\
\hline GPS $^{\text {a }}$ location (Q4) & $28(35)$ & $26(33)$ & $26(33)$ & -0.07 & .60 & 0.18 & .91 \\
SMS $^{\mathrm{b}}$ metadata (Q5) & $24(30)$ & $22(28)$ & $34(43)$ & 0.13 & .31 & 1.00 & .61 \\
SMS contents (Q6) & $16(20)$ & $21(27)$ & $42(53)$ & 0.02 & .13 & 6.30 & .04 \\
Calendar (Q7) & $26(33)$ & $26(33)$ & $27(34)$ & -0.03 & .83 & 4.73 & .09 \\
Screen on/off (Q8) & $36(46)$ & $18(23)$ & $25(32)$ & 0.00 & .97 & 0.48 & .79 \\
Motion sensors (Q9) & $33(42)$ & $20(26)$ & $25(32)$ & -0.04 & .76 & 1.18 & .55 \\
Audio metadata (Q10) & $16(20)$ & $18(23)$ & $46(58)$ & 0.25 & .04 & 4.58 & .10 \\
Audio keywords (Q11) & $14(18)$ & $20(25)$ & $46(58)$ & 0.29 & .02 & 2.25 & .33 \\
Audio unrestrained (Q12) & $15(19)$ & $25(31)$ & $40(50)$ & 0.32 & .01 & 4.67 & .10 \\
\hline
\end{tabular}

${ }^{\mathrm{a}}$ GPS: Global Positioning System.

${ }^{\mathrm{b}} \mathrm{SMS}$ : short message service. 
Figure 1. Respondent willingness to install app and grant permissions. GPS: Global Positioning System; SMS: short message service.

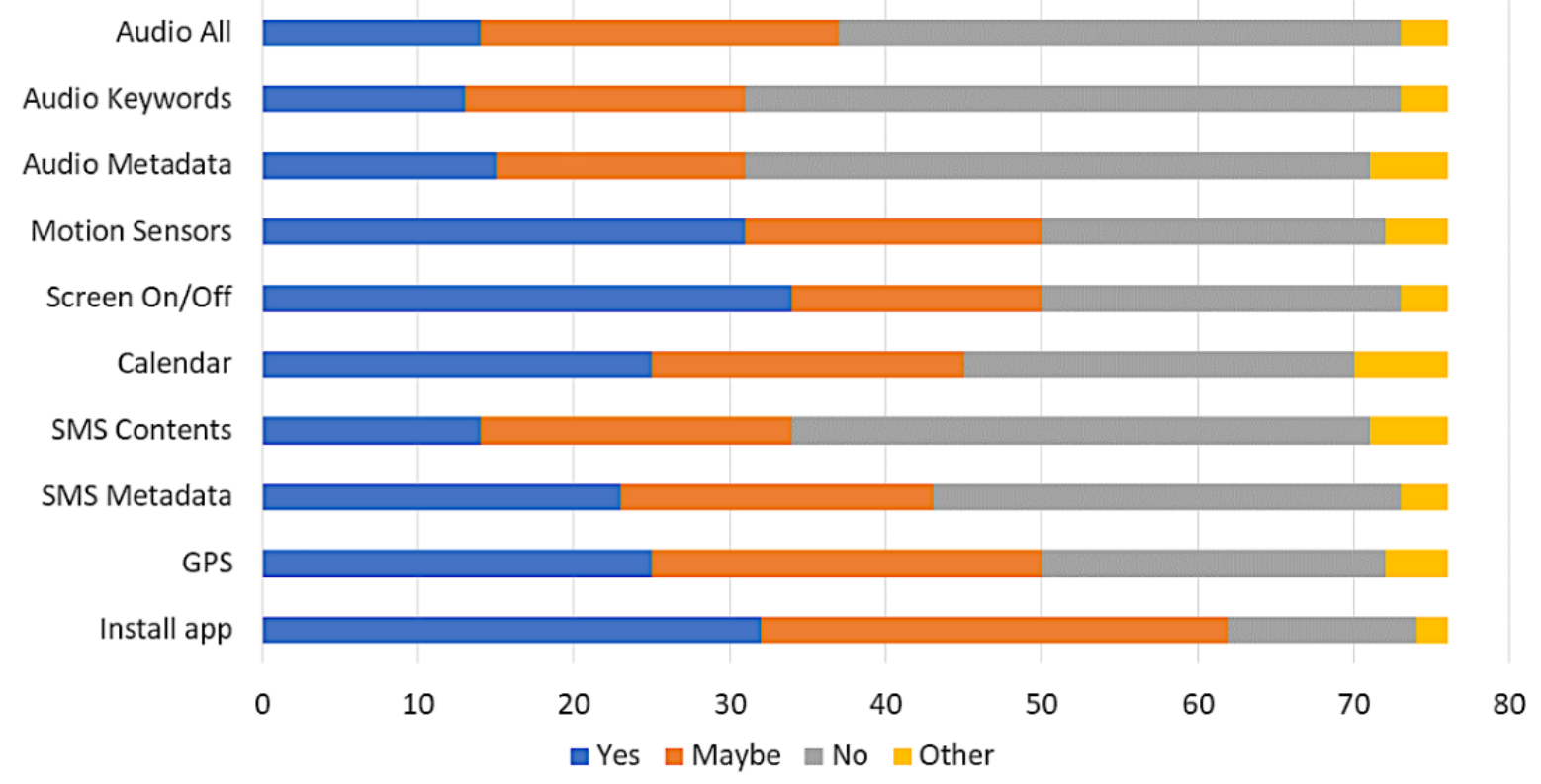

\section{Discussion}

\section{Principal Findings}

Mobile phone ownership rates in the patient population surveyed in this study are high, with $89 \%$ of respondents reporting that they own a mobile phone and use it daily and $85 \%$ of patients connect to the internet with it. These results indicate that, in general, lack of mobile phone ownership itself will not present a barrier to the use of mental health monitoring apps in the future. This is further evidenced by American [24] and Canadian [25] mobile phone ownership statistics.

The vast majority of respondents reported owning either an iPhone (45\%) or an Android device (47\%). This corroborates surveys conducted by Gartner in 2018 [26] which indicate that Android and iOS, collectively, comprise $99.8 \%$ of the mobile phone operating systems. As each platform can require significant effort to support, this is relatively good news that suggests that development solely on iOS and Android platforms is sufficient to support the vast majority of patients.

We observe that overall respondents' reception toward the notion of installing a mental health monitoring app is generally positive, with $84 \%$ answering either yes or maybe when asked if they would install and use such an app on their mobile phone. This finding shows that there is a general positive interest in using mobile phone apps to aid in mental health assessment. Considering that the questionnaire expresses that such an app is believed to help both clinicians and patients but makes no claims about proven effectiveness nor does it quantify said effectiveness in any way, it is plausible that if such apps are to be developed and proved to be effective that rates of adoption may be higher than reported in this study once patients are presented with these findings.

Respondent willingness to provide access to particular sources of data varies from a minimum of $43 \%$ answering yes or maybe in the case of audio metadata or keyword extractions (questions 10 and 11) to a maximum of $68 \%$ answering yes or maybe in the case of screen state (question 8). We feel that these results are encouraging considering the survey does not allay any potential fears that may be held by the respondents with regard to data security or data access. In a production-ready app, data security is likely to be a considerable point of focus, with efforts to encrypt data in transit and at rest. Furthermore, it may be possible to develop automated software algorithms to process much of the raw data and report higher level statistics of interest to clinicians $[27,28]$, addressing patient fears that others would be scrutinizing them personally by, for example, reading their text messages or listening to their audio recordings. As our survey did not address any of these points, it may be possible that responses would be more positive given these guarantees.

It is worth noting that data sources that are low resolution in terms of providing personal or private information, such as screen state (Q8) and motion sensor data (Q9), are the most likely to be granted. Contrast this with sources of data that offer much more insight into a person's private life, such as the contents of SMS messages (Q6) and unrestrained audio recording and analysis (Q12), which are among the least likely to be granted (only $20 \%$ and $19 \%$ yes responses, respectively). This could be interpreted as evidence toward the hypothesis that fear of scrutiny is responsible for unwillingness to provide access to data. If that hypothesis was supported, then this suggests that any automated analysis of data that removes humans from direct observation of the source data may be a method to improve patient willingness to provide data access. Further research is required to explore this hypothesis, however.

\section{Comparison With Other Studies}

The rates of mobile phone ownership and use measured in this work is roughly in line with previous research in other areas. The results reported in this study are most similar to those measured in the United States, with a high 70\% [29] to $80 \%$ range [30]. The predominance of Android and iOS devices within the population under study is also in line with current market statistics [26]. The mobile phone ownership and use 
measured in this study was somewhat lower than the $96 \%$ rate measured by Zhang et al [31] in a Chinese population.

While existing work demonstrates that mobile phone and/or wearable-based health assessment tools are being adopted despite concerns around privacy [21,22], the authors are unaware of any studies that have attempted to determine precisely which sources of data cause most concern. In the broader field of mobile phone apps in general (ie, without a focus on mental health care apps), Felt et al [32] found that SMS messages were the data source that was most cause for concern, more so than Global Positioning System (GPS) location. While they did not consider audio recordings, the identification of SMS messages being more invasive of privacy than GPS location is in line with our results. A similarly broad study into mobile phone user perceptions of privacy and security found that older users exhibited more privacy and security concerns [33]. This is in contrast with the population studied in this work, as we have measured a positive relationship between age and willingness to consent to audio recordings (ie, older people are more willing to consent to audio collection).

\section{Limitations}

One limitation of the study is the small, concentrated population of respondents. All respondents presumably live within the Toronto area, and it is not clear how these results may generalize to the greater Canadian population or beyond. Another limitation of the study is the survey design. It is clear that respondents, in general, require more information to provide a sense of their willingness to provide access to data, as the proportion of maybe responses averaged across questions 4 through 12 was nearly one-third of respondents (28\%). As mentioned earlier, 2 key pieces of information that would help respondents make more informed decisions are the effectiveness of the app in helping to monitor or manage their mental health if the data are provided and the risks involved and the steps being taken to protect the patient's privacy. Conveying both of these pieces of information to prospective app users will be a challenge for health care providers willing to employ mobile mental health apps.

Another fundamental limitation of this study is one inherent to surveys in general: it is not clear that survey respondents who expressed interest in the hypothetical app and willingness to consent to collection of their data through the app would actually consent in a real-life scenario involving real mental health apps. We surmise this would depend upon how effective the apps were shown to be and what patient perception of the risks would be.

Finally, it would be interesting for future work to determine if there were any measurable differences between how patients with different disorders might consent to access to their data. One interesting hypothesis to test would be whether patients with social anxiety disorder, who fear evaluation and scrutiny, would be less likely to provide data access, possibly due to the fear of observation or judgment from others characteristic of the disorder [34].

\section{Conclusion}

Given the potential for mobile technology to help patients monitor their mental health symptoms in a passive and pervasive way, it is helpful for researchers to understand how patients may respond to requests for access to their personal data. General interest in such an app is moderate, with $41 \%$ of respondents indicating they would install a monitoring app and $43 \%$ of respondents indicating they may install such an app. Willingness to provide data collection across different sources ranges from $18 \%$ to $46 \%$, with more intrusive or private sources of data being more likely to be withheld. Finally, we support previous findings [24,25] that show mobile phone technology adoption alone will not pose a significant problem to fielding mental health apps, as $85 \%$ of respondents reported using an internet-connected mobile phone daily.

\section{Acknowledgments}

This research was funded in part by the Natural Sciences and Engineering Research Council Discovery Grant number RGPIN-2014-05032.

\section{Conflicts of Interest}

MAK has been a consultant or advisory board member for GlaxoSmithKline, Lundbeck, Eli Lilly, Boehringer Ingelheim, Organon, AstraZeneca, Jannsen-Ortho, Solvay, Bristol-Myers Squibb, Shire, Sunovion, Pfizer, Purdue, Merck, Astellas, and Bedrocan. He has undertaken research for GlaxoSmithKline, Lundbeck, Eli Lilly, Organon, AstraZeneca, Jannsen-Ortho, Solvay, Genuine Health, Shire, Bristol-Myers Squibb, Takeda, Pfizer, Hoffman La Rosche, Biotics, Purdue, Astellas, and Forest. He has received honoraria from GlaxoSmithKline, Lundbeck, Eli Lilly, Boehringer Ingelheim, Organon, AstraZeneca, Janssen-Ortho, Solvay, Bristol-Myers Squibb, Shire, Sunovion, Pfizer, Purdue, Merck, Astellas, and Bedrocan. MAK has received research grants from the Canadian Institutes of Health Research, Sick Kids Foundation, Centre for Addiction and Mental Health Foundation, Canadian Psychiatric Research Foundation, Canadian Foundation for Innovation, and the Lotte and John Hecht Memorial Foundation.

\section{References}

1. Meyer G, Finn S, Eyde L, Kay G, Moreland K, Dies R, et al. Psychological testing and psychological assessment: a review of evidence and issues. Am Psychol 2001 Feb;56(2):128-165. [Medline: 11279806]

2. Rogler LH, Malgady RG, Tryon WW. Evaluation of mental health. Issues of memory in the Diagnostic Interview Schedule. J Nerv Ment Dis 1992 Apr;180(4):215-222. [Medline: 1556561]

3. van de Mortel T. Faking it: social desirability response bias in self-report research. Aust J Adv Nurs 2008;25(4):40 [FREE Full text] 
4. John OP, Robins RW. Accuracy and bias in self-perception: individual differences in self-enhancement and the role of narcissism. J Pers Soc Psychol 1994 Jan;66(1):206-219. [Medline: 8126650]

5. Rainie L, Zickuhr K. Americans' views on mobile etiquette, 2015. Washington: Pew Internet and American Life Project URL: http://assets.pewresearch.org/wp-content/uploads/sites/14/2015/08/2015-08-26_mobile-etiquette_FINAL.pdf [accessed 2016-08-31] [WebCite Cache ID 6kAwHhlIt]

6. Harari GM, Müller SR, Aung MS, Rentfrow PJ. Smartphone sensing methods for studying behavior in everyday life. Curr Opin Behav Sci 2017 Dec;18:83-90. [doi: 10.1016/j.cobeha.2017.07.018]

7. Mafrur R, Nugraha IGD, Choi D. Modeling and discovering human behavior from smartphone sensing life-log data for identification purpose. Hum Cent Comput Inf Sci 2015 Oct 12;5(1):31. [doi: 10.1186/s13673-015-0049-7]

8. Pei L, Guinness R, Chen R, Liu J, Kuusniemi H, Chen Y, et al. Human behavior cognition using smartphone sensors. Sensors (Basel) 2013;13(2):1402-1424 [FREE Full text] [doi: 10.3390/s130201402] [Medline: 23348030]

9. Ferreira D, Kostakos V, Dey AK. AWARE: mobile context instrumentation framework. Front ICT 2015 Apr 20;2. [doi: 10.3389/fict.2015.00006]

10. Asselbergs J, Ruwaard J, Ejdys M, Schrader N, Sijbrandij M, Riper H. Mobile phone-based unobtrusive ecological momentary assessment of day-to-day mood: an explorative study. J Med Internet Res 2016 Mar 29;18(3):e72 [FREE Full text] [doi: 10.2196/jmir.5505] [Medline: 27025287]

11. Faurholt-Jepsen M, Busk J, Frost M, Vinberg M, Christensen EM, Winther O, et al. Voice analysis as an objective state marker in bipolar disorder. Transl Psychiatry 2016 Jul 19;6:e856. [doi: 10.1038/tp.2016.123] [Medline: 27434490]

12. Abdullah S, Matthews M, Frank E, Doherty G, Gay G, Choudhury T. Automatic detection of social rhythms in bipolar disorder. J Am Med Inform Assoc 2016 May;23(3):538-543. [doi: 10.1093/jamia/ocv200] [Medline: 26977102]

13. Ben-Zeev D, Scherer EA, Wang R, Xie H, Campbell AT. Next-generation psychiatric assessment: using smartphone sensors to monitor behavior and mental health. Psychiatr Rehabil J 2015 Sep;38(3):218-226 [FREE Full text] [doi:

10.1037/prj0000130] [Medline: 25844912]

14. Moskowitz DS, Young SN. Ecological momentary assessment: what it is and why it is a method of the future in clinical psychopharmacology. J Psychiatry Neurosci 2006 Jan;31(1):13-20 [FREE Full text] [Medline: 16496031]

15. Place S, Blanch-Hartigan D, Rubin C, Gorrostieta C, Mead C, Kane J, et al. Behavioral indicators on a mobile sensing platform predict clinically validated psychiatric symptoms of mood and anxiety disorders. J Med Internet Res 2017 Mar 16;19(3):e75 [FREE Full text] [doi: 10.2196/jmir.6678] [Medline: 28302595]

16. Clark D, Wells A. A cognitive model of social phobia. In: Heimberg RG, Liebowitz MR, Hope DA, Schneier FR, editors. Social Phobia: Diagnosis, Assessment, and Treatment. 1st edition. New York: Guilford Press; 1995:69-93.

17. Nebeker C, Murray K, Holub C, Haughton J, Arredondo EM. Acceptance of mobile health in communities underrepresented in biomedical research: barriers and ethical considerations for scientists. JMIR Mhealth Uhealth 2017 Jun 28;5(6):e87 [FREE Full text] [doi: 10.2196/mhealth.6494] [Medline: 28659258]

18. Sicari S, Rizzardi A, Grieco L, Coen-Porisini A. Security, privacy and trust in Internet of Things: the road ahead. Comput Netw 2015 Jan;76:146-164. [doi: 10.1016/j.comnet.2014.11.008]

19. Weber RH. Internet of things: privacy issues revisited. Comput Law Secur Rev 2015 Oct;31(5):618-627. [doi: 10.1016/j.clsr.2015.07.002]

20. Weinberg BD, Milne GR, Andonova YG, Hajjat FM. Internet of Things: convenience vs. privacy and secrecy. Bus Horiz 2015 Nov;58(6):615-624. [doi: 10.1016/j.bushor.2015.06.005]

21. Gao Y, Li H, Luo Y. An empirical study of wearable technology acceptance in healthcare. Ind Manag Data Syst 2015 Oct 19;115(9):1704-1723. [doi: 10.1108/IMDS-03-2015-0087]

22. Li H, Wu J, Gao Y, Shi Y. Examining individuals' adoption of healthcare wearable devices: an empirical study from privacy calculus perspective. Int J Med Inform 2016 Apr;88:8-17. [doi: 10.1016/j.ijmedinf.2015.12.010] [Medline: 26878757]

23. Torous J, Friedman R, Keshavan M. Smartphone ownership and interest in mobile applications to monitor symptoms of mental health conditions. JMIR Mhealth Uhealth 2014;2(1):e2 [FREE Full text] [doi: 10.2196/mhealth.2994] [Medline: 25098314]

24. Number of smartphone users in the United States from to 2010 to 2022.: Statista; 2015. URL: https://www.statista.com/ statistics/201182/forecast-of-smartphone-users-in-the-us/ [accessed 2018-08-15] [WebCite Cache ID 71h5Ypcuf]

25. Statistics Canada. 2016. Life in the fast lane: how are Canadians managing URL: https://www150.statcan.gc.ca/n1/en/ daily-quotidien/171114/dq171114a-eng.pdf [accessed 2018-08-15] [WebCite Cache ID 71h5wepMX]

26. Statistica. Global mobile OS market share in sales to end users from 1st quarter 2009 to 2nd quarter 2017 URL: https:/ /www.statista.com/statistics/266219/global-smartphone-sales-since-1st-quarter-2009-by-operating-system/ [accessed 2018-08-15] [WebCite Cache ID 71h69CKT6]

27. McGraw I, Prabhavalkar R, Alvarez R, Arenas M, Rao K, Rybach D, et al. Personalized speech recognition on mobile devices. ICASSP 2016;1(1):5955-5959. [doi: 10.1109/ICASSP.2016.7472820]

28. Andriotis P, Takasu A, Tryfonas T. Smartphone message sentiment analysis. In: Peterson G, Shenoi S, editors. Advances in Digital Forensics. Berlin: Springer; 2014. 
29. Rubanovich CK, Mohr DC, Schueller SM. Health app use among individuals with symptoms of depression and anxiety: a survey study with thematic coding. JMIR Ment Health 2017 Jun 23;4(2):e22 [FREE Full text] [doi: 10.2196/mental.7603] [Medline: 28645891]

30. Torous J, Chan SR, Yee-Marie TS, Behrens J, Mathew I, Conrad EJ, et al. Patient smartphone ownership and interest in mobile apps to monitor symptoms of mental health conditions: a survey in four geographically distinct psychiatric clinics. JMIR Ment Health 2014;1(1):e5 [FREE Full text] [doi: 10.2196/mental.4004] [Medline: 26543905]

31. Zhang H, Zhang H, Wang X, Yang Z, Zhao Y. Analysis of requirements for developing an mHealth-based health management platform. JMIR Mhealth Uhealth 2017 Aug 03;5(8):e117 [FREE Full text] [doi: 10.2196/mhealth.5890] [Medline: 28778840]

32. Felt A, Egelman S, Wagner D. I've got 99 problems, but vibration ain't one: a survey of smartphone users' concerns. SPSM 2012;1(1):33-44. [doi: 10.1145/2381934.2381943]

33. Fife E, Orjuela J. The privacy calculus: mobile apps and user perceptions of privacy and security. Int J Eng Bus Manag 2012 Jan;4:11. [doi: 10.5772/51645]

34. Diagnostic and Statistical Manual of Mental Disorders, 5th Edition. Arlington: American Psychiatric Publishing; 2013.

\title{
Abbreviations
}

GPS: Global Positioning System

SMS: short message service

START: Stress, Trauma, Anxiety, Rehabilitation, Treatment

\author{
Edited by G Eysenbach; submitted 18.12.17; peer-reviewed by S Schueller, J Andrews; comments to author 16.03.18; revised version \\ received 10.05.18; accepted 21.06.18; published 29.08 .18 \\ Please cite as: \\ Di Matteo D, Fine A, Fotinos K, Rose J, Katzman M \\ Patient Willingness to Consent to Mobile Phone Data Collection for Mental Health Apps: Structured Questionnaire \\ JMIR Ment Health 2018;5(3):e56 \\ URL: http://mental.jmir.org/2018/3/e56/ \\ doi: $10.2196 /$ mental.9539 \\ PMID: 30158102
}

CDaniel Di Matteo, Alexa Fine, Kathryn Fotinos, Jonathan Rose, Martin Katzman. Originally published in JMIR Mental Health (http://mental.jmir.org), 29.08.2018. This is an open-access article distributed under the terms of the Creative Commons Attribution License (https://creativecommons.org/licenses/by/4.0/), which permits unrestricted use, distribution, and reproduction in any medium, provided the original work, first published in JMIR Mental Health, is properly cited. The complete bibliographic information, a link to the original publication on http://mental.jmir.org/, as well as this copyright and license information must be included. 